\title{
Umbilicated Keratotic Papule on the Scalp
}

Kazuki Mitsuru Matsuda, MD; Haruko Nishio, MD; Haruko Hino, MD, PhD; Shinji Kagami, MD, PhD

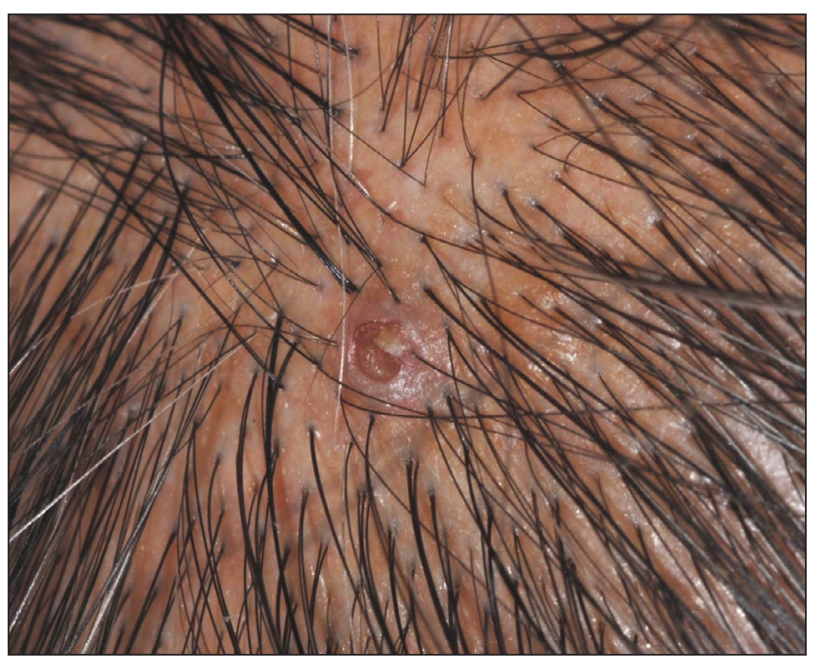

A 72-year-old man was referred to our dermatology clinic for evaluation of a solitary papule on the scalp measuring $3.2 \mathrm{~mm}$ in diameter with a keratotic umbilicated center of 1 year's duration. His medical history included acute appendicitis. Treatment with fusidic acid ointment $2 \%$ was unsuccessful. The papule was hard without tenderness on palpation. An excisional biopsy was performed under local anesthesia.

\section{WHAT'S YOUR DIAGNOSIS?}
a. Darier disease
b. keratoacanthoma
c. seborrheic keratosis
d. verruca vulgaris
e. warty dyskeratoma

Drs. Matsuda, Hino, and Kagami are from the Department of Dermatology, Kanto Central Hospital of the Mutual Aid Association of Public School Teachers, Tokyo, Japan. Dr. Nishio is from Tsurumaki Dermatology, Tokyo.

The authors report no conflict of interest.

Correspondence: Kazuki Mitsuru Matsuda, MD, Department of Dermatology, Kanto Central Hospital of the Mutual Aid Association of Public School Teachers, 6-25-1, Kamiyoga, Setagaya-ku, Tokyo 1588531, Japan (mkazuki.kom@gmail.com).

doi:10.12788/cutis.0142 


\section{THE DIAGNOSIS: Warty Dyskeratoma}

W arty dyskeratoma (WD) is a benign cutaneous tumor that was first described in 1954 as isolated Darier disease (DD). In 1957, Szymanski ${ }^{1}$ renamed it warty dyskeratoma as a distinct condition from DD. Warty dyskeratoma typically presents as a fleshcolored to brownish, round, well-demarcated, and slightly elevated papule or nodule accompanied by an umbilical invagination at the center. It most commonly arises on the scalp, face, or neck. ${ }^{2}$ In contrast to DD, familial occurrence is uncommon. It usually is difficult to distinguish WD from other conditions such as seborrheic keratosis, verruca vulgaris, or keratoacanthoma due to its macroscopic features. Therefore, histopathologic investigation is necessary for a precise diagnosis.

In our case, histologic investigation revealed a symmetric cup-shaped invagination filled with acantholytic and dyskeratotic keratinocytes with no atypia or mitotic figures (Figure, A). The bottom of the invagination was occupied with numerous villi covered by a single layer of basal cells (Figure, B). At the edge of the invagination, corps ronds and grains were observed in the granular and cornified layers, respectively (Figure, C).

The hallmark histopathologic findings are acantholysis and dyskeratosis just above the basal cell layer, called focal acantholytic dyskeratosis. The differential diagnosis includes other disorders associated with focal acantholytic dyskeratosis, such as DD and acantholytic squamous cell carcinoma. ${ }^{3}$ Distinguishing WD from DD may be difficult in rare cases with multiple lesions. ${ }^{4}$ In such cases, an autosomal-dominant inheritance pattern and younger age of onset should prompt clinícians to seek for mutations in the ATPase sarcoplasmic/endoplasmic reticulum $\mathrm{Ca} 2+$ transporting 2 gene, ATP2A2, for the diagnosis of DD. ${ }^{5}$ Additionally, the presence of atypia or mitotic figures will rule out malignant disorders such as squamous cell carcinoma.

Although the pathogenesis of WD is not fully understood, most clinicians consider it a follicular adnexal neoplasm because the lesions often are connected to the pilosebaceous unit on microscopic observation. ${ }^{6}$ Although WD-like lesions arising from the oral mucosa have been reported, $^{7}$ their etiology may be different from WD because the oral mucosa lacks hair follicles. ${ }^{8}$ The term warty leads to speculation of the contribution of human papillomavirus to the pathogenesis of $\mathrm{WD}$, but this has been questioned due to the negative result of viral DNA detection from WD lesions by polymerase chain reaction analysis. ${ }^{2}$ Therefore, the term follicular dyskeratoma has been suggested as a novel denomination that reflects its etiology more precisely. ${ }^{2}$

The efficacy of topical treatment has not yet been established. Cryosurgery is another therapeutic option,
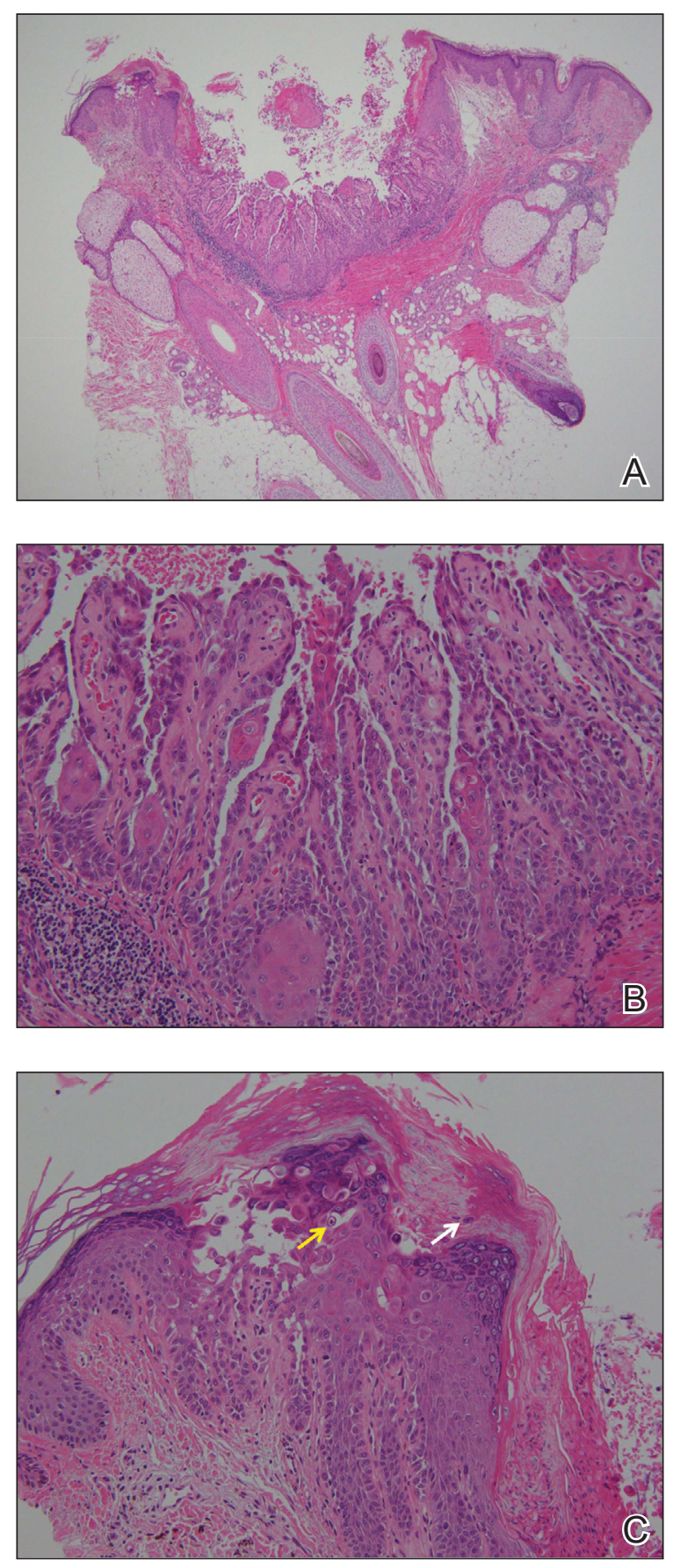

Warty dyskeratoma. A, A symmetric cup-shaped invagination filled with acantholytic and dyskeratotic keratinocytes (H\&E, original magnification $\times 40$ ). B, Numerous villi covered by a single layer of basal cells at the bottom of the invagination (H\&E, original magnification $\times 200$ ). $\mathrm{C}$, At the edge of the invagination there were corps ronds (yellow arrow) in the granular layer and grains (white arrow) in the cornified layer $(\mathrm{H \& E}$, original magnification $\times 200)$. 
but it sometimes fails. ${ }^{9}$ As performed in our patient, excisional biopsy is the most reasonable treatment option to obtain both complete removal and precise diagnosis.

\section{REFERENCES}

1. Szymanski FJ. Warty dyskeratoma; a benign cutaneous tumor resembling Darier's disease microscopically. AMA Arch Dermatol. 1957; 75:567-572.

2. Kaddu S, Dong H, Mayer G, et al. Warty dyskeratoma-“'follicular dyskeratoma": analysis of clinicopathologic features of a distinctive follicular adnexal neoplasm. J Am Acad Dermatol. 2002;47:423-428.

3. DiMaio DJ, Cohen PR. Incidental focal acantholytic dyskeratosis. J Am Acad Dermatol. 1998;38(2, pt 1):243-247.
4. Wang S, Bai J, Si Z, et al. Multiple warty dyskeratoma: a case report and review of the literature. Int J Clin Exp Med. 2018;11:5241-5244.

5. Sakuntabhai A, Ruiz-Perez V, Carter S, et al. Mutations in ATP2A2, encoding a Ca2+ pump, cause Darier disease. Nat Genet. 1999;21:271-277.

6. Graham JH, Helwig EB. Isolated dyskeratosis follicularis. AMA Arch Dermatol. 1958;77:377-389.

7. Kaugars GE, Lieb RJ, Abbey LM. Focal oral warty dyskeratoma. Int J Dermatol. 1984;23:123-130.

8. Allon I, Buchner A. Warty dyskeratoma/focal acantholytic dyskeratosis-an update on a rare oral lesion. J Oral Pathol Med. 2012;41:261-267.

9. Nakagawa T, Umekage K, Komatsu S, et al. Case of warty dyskeratoma with unique dermoscopic features. J Dermatol. 2018;45:E74-E75. 